\title{
Suplementos para terminação de ovinos em pastos de Brachiaria brizantha cv. Marandu
}

\section{Supplements for finishing sheep in Brachiaria brizantha cv. Marandu pasture}

\author{
Daniel Marino Guedes de Carvalho ${ }^{1 *}$; Luciano da Silva Cabral2; \\ Janaina Januario da Silva ${ }^{2}$; Joadil Gonçalves de Abreu²; \\ Rosemary Laís Galati; Gessy Gabriela de Paula Gentile ${ }^{3}$; \\ Lázaro Manoel de Camargo ${ }^{4}$; Juliane Quenoizoré Soares ${ }^{5}$; João Rufino Junior ${ }^{6}$
}

\section{Resumo}

Objetivou-se avaliar a suplementação sobre a resposta produtiva, os parâmetros nutricionais e o custo de produção de ovinos em pasto de Brachiaria brizantha cv. Marandu. O experimento teve duração de 84 dias, e foram utilizadas 20 cordeiras deslanadas sem raça definida com idade e peso corporal inicial de quatro meses e $21,73 \mathrm{~kg}$, além de quatro animais canulados no rúmen com 12 meses e 55,00 $\mathrm{kg}$ de peso corporal, distribuídos em quatro piquetes de 0,1 ha providos de bebedouros e cochos, em que foram avaliados os seguintes tratamentos: mistura mineral, farelo de soja, grão de soja e caroço de algodão. Foram observados ganhos de peso médio diário de 0,$061 ; 0,080 ; 0,060$ e $0,080 \mathrm{~kg} \mathrm{dia}^{-1}$, respectivamente, para a mistura mineral, farelo de soja, grão de soja e caroço de algodão. Os valores médios de $\mathrm{pH}$ ruminal foram 6,$16 ; 6,18 ; 6,25$ e 6,23, respectivamente, para os suplementos mineral, farelo de soja, grão de soja e caroço de algodão e os valores para nitrogênio amoniacal ruminal foram 11,$10 ; 24,77 ; 22,31$ e $29,37 \mathrm{mg} \mathrm{dL}^{-1}$ de líquido ruminal, respectivamente, para suplementos mineral, farelo de soja, grão de soja e caroço de algodão. Os suplementos farelo de soja e caroço de algodão aumentaram o ganho de peso em $8,75 \%$, em relação, aos animais mantidos apenas com mistura mineral, diminuindo a idade ao abate dos animais.

Palavras-chave: Ganho de peso, nitrogênio amoniacal, nitrogênio ureico, $\mathrm{pH}$, suplementação

\begin{abstract}
The objective was to evaluate the supplementation on the productive response, nutritional parameters and the cost of production of sheep grazing grass Marandu. The experiment lasted 84 days and 20 lambs were used with age and initial body weight of $21.73 \mathrm{~kg}$ and four months, as well four rumen fitted sheep of 12 months and $55.00 \mathrm{~kg}$ of body weight, divided into four paddocks of 0.1 ha provided, with water and supplements dispenser, to evaluated the following treatments: mineral mix, soybean meal, soybean seed and cottonseed whole. For the average daily gain observed were of $0.061,0.080,0.060$ and 0.080
\end{abstract}

${ }^{1}$ Prof., Universidade Federal de Mato Grosso, UFMT, Barra do Garças, MT. E-mail: danielguedes14@yahoo.com.br

2 Profs., Universidade Federal de Mato Grosso, UFMT, Cuiabá, MT. E-mail: cabrals@ufmt.br; janajanu@hotmail.com; joadil@ terra.com.br; galati@gmail.com

3 Mestre, UFMT, Cuiabá, MT. E-mail: gessigabi@hotmail.com

${ }^{4}$ Prof., Universidade de Cuiabá, UNIC, Cuiabá, MT. E-mail: lazarocamargo@yahoo.com.br

5 Discente de Mestrado, UFMT, Cuiabá, MT. E-mail: juliane_qs@hotmail.com

${ }^{6}$ Discente de Doutorado, UFMT, Cuiabá, MT. E-mail: rufino@zootecnista.com.br

* Autor para correspondência 
$\mathrm{kg}$ day-1, respectively, for the mineral mix, soybean meal, soybean seed and cottonseed whole. The average $\mathrm{pH}$ values were $6.16,6.18,6.25$ and 6.23 , respectively, for the mineral supplements, soybean meal, soybean seed and cottonseed whole, and values for rumen ammonia nitrogen were 11, 10, 24.77, 22.31 and $29.37 \mathrm{mg} \mathrm{dL}-1$ of rumen fluid, respectively. Supplements of soybean meal and cottonseed whole increased weight gain at $8.75 \%$ compared to animals maintained only with mineral salt, however, the mineral salt produced weight gain with lower cost.

Key words: Ammonia nitrogen, body weight, $\mathrm{pH}$, supplementation, ureic nitrogen

\section{Introdução}

A suplementação da dieta de animais com misturas múltiplas no período seco é prática comum pelos produtores, pois proporciona elevada relação custo/benefício. Contudo, o uso de suplementos múltiplos no período das águas, ainda necessita de mais investigações para dirimir várias dúvidas decorrentes da interação entre pasto e suplemento, incluindo questões relativas ao uso de compostos nitrogenados não-proteicos (CNNP), como a ureia (PORTO et al., 2009).

Mesmo a suplementação proporcionando ganhos de peso diferenciais inferiores aos observados na época seca, a adoção desta técnica pode proporcionar diminuição da idade de abate dos animais suplementados, liberando áreas de pastagens para outros lotes de animais mais eficientes serem terminados (CABRAL et al., 2008a). A suplementação alimentar surge, neste contexto, como alternativa tecnológica efetiva e importante para acelerar o ganho de peso animal e para potencializar a utilização dos recursos forrageiros disponíveis (EUCLIDES et al., 2009).

Isso tem sido amparado principalmente no fato de que, nessa época do ano, as forrageiras tropicais apresentam teores médios de proteína bruta $(\mathrm{PB})$ que satisfazem as necessidades dos microrganismos ruminais, isto é, acima de 7\% de PB. Este valor é considerado por Minson (1990) como não limitante à atividade dos microrganismos do rúmen, entretanto, essa atividade é adequada apenas para a manutenção dos animais e com isso, pode comprometer a digestibilidade da forragem altamente fibrosa (LAZZARINI et al., 2009).
A deficiência ruminal de compostos nitrogenados (N) nas formas de amônia, aminoácidos ou peptídeos pode influenciara regulação daingestão dealimentos. Quando o suprimento de $\mathrm{N}$ ao rúmen, originário do material ingerido ou da reciclagem endógena, não atende aos requisitos microbianos, podem ocorrer limitações ao crescimento microbiano e redução da digestão da parede celular vegetal, diminuindo com isso consumo (SNIFFEN et al., 1992). Nesse contexto, o fornecimento de suplementos com fontes de proteína de alta ou baixa degradabilidade ruminal pode ser uma alternativa para aumentar os níveis de nitrogênio amoniacal ruminal e proporcionar aos microrganismos ruminais condição mais favorável à degradação da fração potencialmente degradável da fibra da forragem.

Com o advento da expansão das fronteiras agrícolas, sobretudo da cultura da soja e do algodão, é cada vez mais comum o uso do grão de soja e caroço de algodão in natura na alimentação de ruminantes como substitutos do farelo de soja, pois consiste numa forma do produtor diminuir os custos de produção, sem prejudicar o desempenho dos animais, uma vez que consegue produzir estes produtos a custos relativamente baixos e ainda economizar com o transporte.

Apesar da estratégia de suplementação ser dependente da meta de desempenho animal que se deseja alcançar, sua escolha deverá também ser fundamentada em análise econômica. Assim, a rentabilidade da estratégia de suplementação alimentar constitui-se no norteador da escolha do suplemento a ser utilizado (EUCLIDES et al., 2009). 
Desta forma, objetivou-se de avaliar suplementos com diferentes fontes proteicas sobre o desempenho animal, parâmetros nutricionais e custo de produção de ovinos mantidos em pastos de Brachiaria brizantha cv. Marandu na época na época da transição águas-seca.

\section{Material e Métodos}

O experimento foi conduzido nas dependências do Setor de Ovinocultura da fazenda experimental da Universidade Federal de Mato Grosso, localizada a $30 \mathrm{~km}$ de Cuiabá, no município de Santo Antônio de Leverger - MT, na região da Baixada Cuiabana, com início em 03 de Maio e término em 28 de Julho de 2009, totalizando 84 dias experimentais. O local do experimento encontra-se na altitude $141 \mathrm{~m}$ e Latitude $15^{\circ} 51^{\prime}$ Sul e Longitude $56^{\circ} 04^{\prime}$ Oeste. O clima da região é do tipo Cwa segundo a classificação de Koepen, tropical, sazonal, com duas estações bem definidas: verão chuvoso (outubro à março) e inverno seco (abril à setembro).

A área destinada aos animais para a avaliação do desempenho foi constituída por quatro piquetes de 0,1 ha cada, formados com a gramínea Brachiaria brizanta cv. Marandu, adubada com $30 \mathrm{~kg}$ de nitrogênio por ha e vedada no início do mês de Fevereiro, providos de bebedouros e cochos cobertos. Os dados meteorológicos do período em que o experimento foi conduzido e dos dois meses que antecederam ao início do experimento foram obtidos na estação meteorológica da UFMT e estão na Tabela 1 .

Tabela 1. Precipitação pluviométrica (PP) e temperaturas máximas (TM), mínimas (TMI) e médias (TMP) durante o período experimental.

\begin{tabular}{ccccc}
\hline \multirow{2}{*}{ Meses } & PP & TM & TMI & TMP \\
\cline { 2 - 5 } & $(\mathrm{mm})$ & & $\left({ }^{\circ} \mathrm{C}\right)$ & 23,30 \\
\hline Março & 272,90 & 33,00 & 22,40 & 27,50 \\
Abril & 111,40 & 32,60 & 20,10 & 25,90 \\
Maio & 43,20 & 31,70 & 16,80 & 22,75 \\
Junho & 60,50 & 28,70 & 17,40 & 24,45 \\
Julho & 37,60 & 31,50 & \\
\hline
\end{tabular}

Fonte: Estação meteorológica da fazenda experimental da UFMT.

Para avaliação do desempenho animal, foram utilizados 20 cordeiras, deslanadas sem raça definida, com idade e peso corporal médio inicial de quatro meses e $21,73 \mathrm{~kg}$, respectivamente, distribuídas aleatoriamente entre os tratamentos (suplementos), assim constituídos: MM, mistura mineral (testemunha); SFS, mistura mineral, farelo de soja, casca do grão de soja, ureia/sulfato de amônio (9:1); SGS, mistura mineral, grão de soja, casca do grão de soja, ureia/sulfato de amônio (9:1); SCA, mistura mineral, caroço de algodão, casca do grão de soja, ureia/sulfato de amônio (9:1). Os animais foram pesados no início e final do experimento sem jejum prévio, assim como a cada 28 dias (duração de cada período para avaliação do desempenho animal), para monitoramento do desempenho a cada período. Foi realizada a rotação dos animais entre os piquetes a cada 14 dias, para reduzir possíveis variações entre a disponibilidade e qualidade da forragem nos piquetes experimentais. Todos os animais foram submetidos ao controle de ecto e endoparasitos no início e meio do experimento, com o uso de produto a base de closantel, tendo como o critério adotado para realizar a vermifugação a meta 
de manter a quantidade de ovos por grama de fezes (OPG) abaixo de 500 .

A composição percentual dos suplementos com base na matéria natural encontra-se na Tabela 2. Os suplementos foram fornecidos na quantidade de $0,250 \mathrm{~kg}$ animal ${ }^{-1}$ (aproximadamente $1,0 \%$ do peso corporal), diariamente às 10:00 horas. As possíveis sobras foram monitoradas diariamente, no sentido de evitar o desperdício com os suplementos.

Tabela 2. Custo dos ingredientes e composição percentual dos suplementos na matéria natural.

\begin{tabular}{lcccccc}
\hline \multirow{2}{*}{\multicolumn{1}{c}{ Ingrediente }} & \multicolumn{2}{c}{ Valores } & \multicolumn{4}{c}{ Suplementos } \\
\cline { 2 - 7 } & $\mathrm{R} \$ /$ ton & $\mathrm{R} \$ \mathrm{~kg}$ & $\mathrm{MM}$ & $\mathrm{SFS}$ & $\mathrm{SGS}$ & $\mathrm{SCA}$ \\
\hline Farelo de soja $^{3}$ & 800,00 & 0,80 & - & 20,00 & - & - \\
Grão de soja $^{3}$ & 915,00 & 0,92 & - & - & 25,00 & - \\
Caroço de algodão $^{3}$ & 300,00 & 0,30 & - & - & - & 63,00 \\
Casca de soja $^{3}$ & 330,00 & 0,33 & - & 67,00 & 62,00 & 24,00 \\
Uréia+Sulfato de amônio $^{9: 1)^{3}}$ & $1.900,00$ & 1,90 & - & 3,00 & 3,00 & 3,00 \\
Mistura mineral $^{1,3}$ & $1.920,00$ & 1,92 & 100,00 & 10,00 & 10,00 & 10,00 \\
\hline
\end{tabular}

${ }^{3}$ Valores praticados no mercado local; ${ }^{1}$ Mistura mineral comercial para ovinos (Níveis de garantia por kg de produto: $155 \mathrm{~g}$ de cálcio; $65 \mathrm{~g}$ de fósforo; $115 \mathrm{~g}$ de sódio; $6 \mathrm{~g}$ de magnésio; $175 \mathrm{mg}$ de cobalto; $100 \mathrm{mg}$ de cobre; $175 \mathrm{mg}$ de iodo, $1400 \mathrm{mg}$ de manganês; $42 \mathrm{mg}$ de níquel; 27mg de selênio; 6000mg de zinco; flúor (Máx) 650mg); MM: Mistura mineral; SFS: Suplemento farelo de soja; SGS: Suplemento grão de soja; SCA: Suplemento caroço de algodão.

Fonte: Elaboração dos autores.

No primeiro dia de cada período experimental (a cada 28 dias), realizou-se a coleta de amostras da forragem nos diferentes piquetes por meio do corte, a cinco $\mathrm{cm}$ do solo, de dez áreas delimitadas por um quadrado metálico de $0,5 \times 0,5 \mathrm{~m}$, escolhidas aleatoriamente em cada piquete experimental, para estimar a massa de forragem $\left(\mathrm{kg} \mathrm{ha}^{-1}\right)$.

Após a coleta, as amostras de cada piquete foram pesadas e homogeneizadas, e a partir dessas retiraram-se duas alíquotas compostas: uma para avaliação da disponibilidade total de massa seca de forragem total (obtida pela desidratação do material em estufa, obtenção do percentual de matéria seca da forragem e posterior extrapolação da massa de forragem em $1 \mathrm{~m}^{2}$ para $10.000 \mathrm{~m}^{2}$ (um hectare)), em $\mathrm{kg} \mathrm{ha}^{-1}$ (MSFT), e outra para análise das disponibilidades matéria seca por hectare de: lâminas foliares verdes (MSLV), lâminas foliares mortas (MSLM), colmos verdes (MSCV) e colmos mortos (MSCM). A disponibilidade de matéria seca potencialmente digestível em $\mathrm{kg} \mathrm{ha}^{-1}$ (MSpd) foi obtida pela multiplicação da MSTF em $\mathrm{kg} \mathrm{ha}^{-1}$ pela MSpd em porcentagem. A avaliação da forragem ingerida pelos animais foi realizada com uso da técnica da simulação manual de pastejo, por meio da coleta de amostras de pasto em duas linhas diagonais dentro de cada piquete no primeiro dia de cada período experimental, tendo-se procurado manter sempre os mesmos amostradores, com vistas à diminuição na variabilidade dos resultados. Para esta coleta os amostradores procuraram coletar as partes da forragem que estavam sendo consumidas pelos animais, com base em avaliação visual do dossel forrageiro em cada piquete. Também foram feitas amostragens dos suplementos depois de misturados.

As amostras dos suplementos e forragem foram analisadas no Laboratório de Nutrição Animal da Universidade Federal de Mato Grosso e Universidade de Cuiabá, quanto as variáveis matéria 
seca (MS), matéria orgânica (MO), proteína bruta (PB), matéria mineral (MM), extrato etéreo (EE) e fibra em detergente neutro (FDN) realizadas de acordo com as técnicas descritas por Silva e Queiroz (2002). As concentrações de fibra em detergente neutro indigestível (FDNi) foram determinadas por intermédio da digestibilidade in situ, obtida após incubação por 240 horas, segundo o método descrito por Casali et al. (2008). Das amostras destinadas à estimativa da disponibilidade total de MSFT de forragem, foi calculado o percentual de matéria seca potencialmente digestível (MSpd) ofertada aos animais. Esse resultado foi obtido por intermédio do resíduo insolúvel em detergente neutro (FDNi), segundo a equação:

$$
\operatorname{MSpd}=0,98 \mathrm{X}(100-\mathrm{FDN})+(\mathrm{FDN}-\mathrm{FDNi}) ;
$$

Onde:

$0,98=$ coeficiente de digestibilidade verdadeiro do conteúdo celular;

$\mathrm{FDNi}=\mathrm{FDN}$ indigestível.

Os carboidratos totais (CT) da forragem pastejada e dos suplementos foram obtidos pela equação: $\mathrm{CT}=100-(\mathrm{PB}+\mathrm{EE}+\mathrm{CZ})$, segundo Sniffen et al. (1992), sendo os carboidratos não fibrosos (CNF) da forragem obtidos pela diferença entre os CT e o FDN. Já os CNF dos suplementos foram obtidos pela equação: $\mathrm{CNF}=100-[(\% \mathrm{~PB}-\% \mathrm{~PB}$ da ureia $+\%$ ureia) $+\%$ FDN $+\%$ EE $+\%$ cinzas $]$ segundo Hall (2000).

Além dos animais usados para medir o desempenho, foram alocados em cada um dos piquetes um animal canulado no rúmen para avaliação do $\mathrm{pH}$ e das quantidades de nitrogênio amoniacal ruminal, sendo estes animais rotacionados entre os piquetes e suplementos a cada 14 dias. Os animais canulados foram alocados em delineamento quadrado latino $4 \times 4$, e cada período experimental correspondeu a 14 dias. Do primeiro ao $13^{\circ}$ dia experimental, os animais apenas foram adaptados aos suplementos. A coleta de líquido ruminal para a determinação do $\mathrm{pH}$ e do nitrogênio amoniacal $\left(\mathrm{N}_{-} \mathrm{NH}_{3}\right)$ foi realizada no $14^{\circ}$ dia do período experimental. O líquido ruminal foi coletado nos tempos zero hora (antes do fornecimento do suplemento) e 4 horas (4 horas após o fornecimento do suplemento), próximo a abertura da cânula ruminal e filtrado em um béquer com auxílio de duas peneiras de porosidade $2 \mathrm{~mm}$ sobrepostas uma a outra. A leitura do $\mathrm{pH}$ foi realizada com um peagâmetro digital imediatamente após a coleta do material. Após a leitura do $\mathrm{pH}$, uma alíquota de $50 \mathrm{~mL}$ foi acondicionada em recipiente de plástico com 1 $\mathrm{mL}$ de ácido sulfúrico $\left(\mathrm{H}_{2} \mathrm{SO}_{4}\right)$ 1:1 e congelada a $-20^{\circ} \mathrm{C}$, para posteriores análises das quantidades de nitrogênio amoniacal ruminal $\left(\mathrm{N}-\mathrm{NH}_{3}\right)$. No tempo quatro horas após a suplementação também foram coletadas dos animais canulados amostras de sangue por pulsão da veia jugular para a determinação do nitrogênio uréico no plasma (NUP) através de kit comercial de análise.

Para a avaliação econômica, o valor atribuído a tonelada de cada ingrediente foi obtido por cotação de preço no mercado local em três fornecedores diferentes. O custo dos suplementos foi calculado em função do nível de inclusão de cada ingrediente multiplicado pelo seu respectivo preço por unidade de produto $(\mathrm{kg})$. O custo por dia $(\mathrm{R} \$)$ foi calculado multiplicando-se o consumo de suplemento animal/ dia pelo preço por $\mathrm{kg}$ de suplemento. A margem bruta por $\mathrm{kg}$ de ganho foi calculada pela diferença entre o valor pago por $\mathrm{kg}$ de peso corporal (PC) e o custo total com suplemento e mão de obra para que o animal produzisse esse $\mathrm{kg}$ de ganho. Para calcular o custo da mão de obra, assumiu-se a contratação de um funcionário com capacidade para cuidar de 500 animais sendo a sua remuneração mensal de R \$ 545,00 (equivalente a um salário mínimo). Foram considerados os mesmos custos com mãode-obra para os suplementos farelo de soja, grão de soja e caroço de algodão pois estes suplementos foram fornecidos diariamente. Já para MM (mistura mineral) assumiu-se frequência semanal de reabastecimento dos cochos. 
As análises referentes ao desempenho dos animais experimentais foram conduzidas em um delineamento inteiramente casualizado, segundo o modelo estatístico:

$\mathrm{y}_{\mathrm{ij}}=\mu+\mathrm{t}_{\mathrm{i}}+\mathrm{e}_{\mathrm{ij},}$, em que:

$\mu=$ constante geral; $t_{i}=$ efeito do suplemento $i$, sendo $\mathrm{i}=1,2,3$ e $4 ; \mathrm{e}_{\mathrm{ij}}=$ erro aleatório, associado a cada observação, pressuposto NID $\left(0, \sigma^{2}\right)$.

As análises referentes ao $\mathrm{pH}$ e $\mathrm{N}-\mathrm{NH}_{3}$ foram conduzidas em um delineamento quadrado latino, segundo o modelo estatístico:

$$
y i j k=\mu+\alpha i+\beta j+P k+e i j k
$$

em que: $\mu=$ constante geral; $\alpha i=$ efeito do suplemento $i(i=1,2,3$ e 4$) ; \beta j=$ efeito referente ao animal ou sequência de tratamentos $j(j=1,2,3$ e 4); $\mathrm{Pk}=$ efeito referente ao período experimental $\mathrm{k}(\mathrm{k}=1,2,3$ e 4); e eij = erro aleatório, associado a cada observação, pressuposto NID $\left(0, \sigma^{2}\right)$.

Os dados foram analisados por meio de análise de variância e para comparações entre médias, adotouse o teste de Student-Newman-Keulls, sendo todas as análises realizadas por intermédio do programa SAEG - UFV (2001), tendo-se adotado o nível de probabilidade de $5 \%$.

\section{Resultados e Discussão}

Foram observados para o período total do experimento valores médios de massa seca de forragem total (MSFT), de matéria seca potencialmente digestível (MSpD), de lâminas foliares verdes (MSLV), de lâminas foliares mortas (MSLM), de colmos verdes (MSCV) e de colmos mortos (MSCM) na pastagem de 4.330; 2.100; 730; $1.130 ; 2.080$ e $460 \mathrm{~kg} \mathrm{ha}^{-1}$, respectivamente (Figura 1).

Figura 1. Massa seca de forragem total (MSFT), de matéria seca potencialmente digestível (MSpd), de lâmina foliares verdes (MSLV), de lâminas foliares mortas (MSLM), de colmos verdes (MSCV) e de colmos mortos (MSCM) do capim Marandu em cada período experimental.

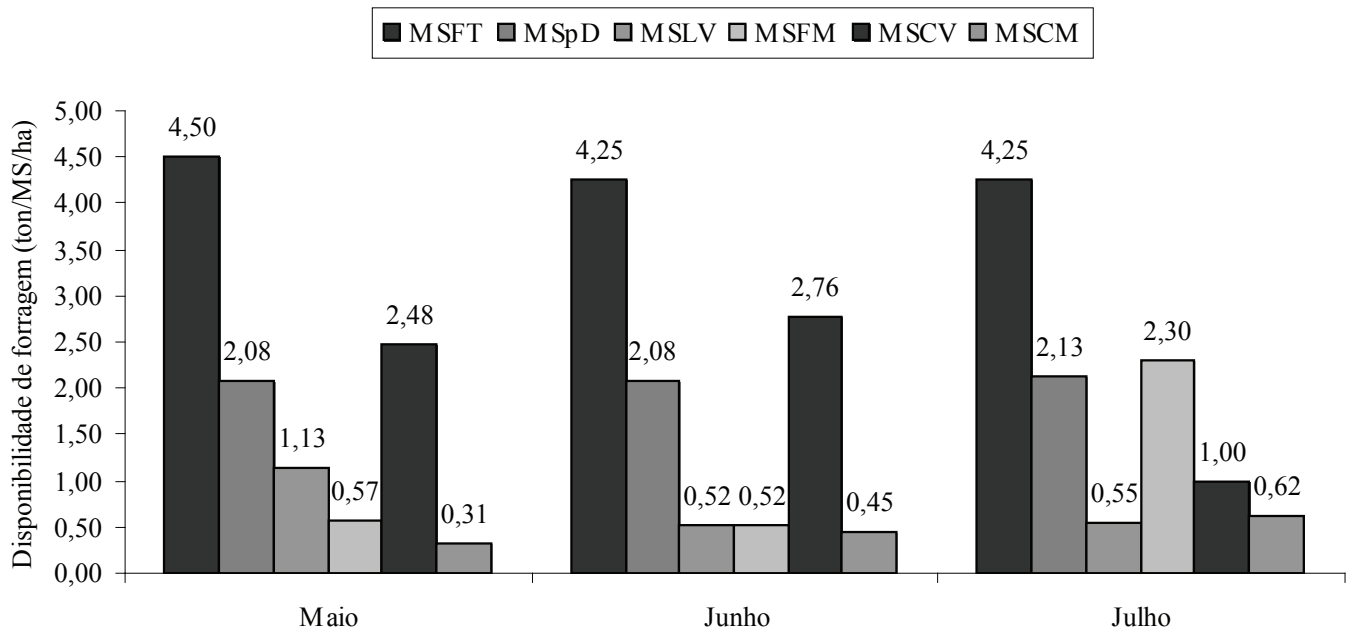

Fonte: Elaboração dos autores.

Os baixos valores encontrados para a variável MSLV para os meses de Junho e Julho são reflexo da grande capacidade seletiva dos ovinos, que consomem preferencialmente lâmina foliar verde em relação a colmos, por ser uma dieta mais adequada as suas exigências nutricionais. A forragem disponível se caracterizava pela elevada proporção de colmos e reduzida proporção de 
lâminas foliares verdes, o que diminui a qualidade da forragem disponível (BRÂNCIO et al., 2003), sendo o desempenho animal afetado pela estrutura do pasto (TRINDADE et al., 2007).

É sabido que em sistemas de produção animal a pasto, o consumo é influenciado pela disponibilidade de forragem. Assim os valores encontrados no presente estudo, para MSLV, contribuíram para o desempenho alcançado pelos animais. Segundo Euclides et al. (2000), no caso de pastagens tropicais, onde há um grande acúmulo de material senescente, a pressão de pastejo deve ser expressa em massa de forragem verde e especialmente como lâminas foliares verdes. Pois não há relação entre o desempenho animal e produção por hectare quando a pressão de pastejo é calculada com base na massa seca total de forragem (MST), mas é positiva com o cálculo em matéria seca verde (MSV). De fato, quando disponível, o animal tende a selecionar apenas folhas verdes e a recusar as folhas secas e os colmos.

Foram observados para o período total do experimento valores médios para ofertas de massa de forragem total (OMSFT), de matéria seca potencialmente digestível (OMSpd), de lâminas foliares verdes (OMSLV), de laminas foliares mortas (OMSLM), de colmos verdes (OMSCV) e de colmos mortos (OMSCM) na pastagem de 15,02; 7,12; 2,62; 3,$71 ; 7,35$ e $1,55 \%$ do PC, respectivamente (Figura 2). Considerando o consumo de matéria seca de forragem de $2,70 \%$ do PC para ovinos com PC médio de $31,00 \mathrm{~kg}$ animal ${ }^{-1}$, obtidos por Ribeiro (2008) em pastagens e capim Aruana irrigado, o valor médio para OMSFT observado nesse experimento é 4,56 vezes a capacidade de consumo dos animais, garantindo assim a oportunidade dos animais realizarem o pastejo seletivo, consumindo forragem com valor nutritivo mais adequado as suas exigências nutricionais.

Figura 2. Ofertas diárias de Massa seca de forragem total (OMSFT), de matéria seca potencialmente digestível (OMSpd), de lâmina foliares verdes (OMSLV), de lâminas foliares mortas (OMSLM), de colmos verdes (OMSCV) e de colmos mortos (OMSCM) do capim Marandu em cada período experimental em porcentagem do peso corporal dos animais.

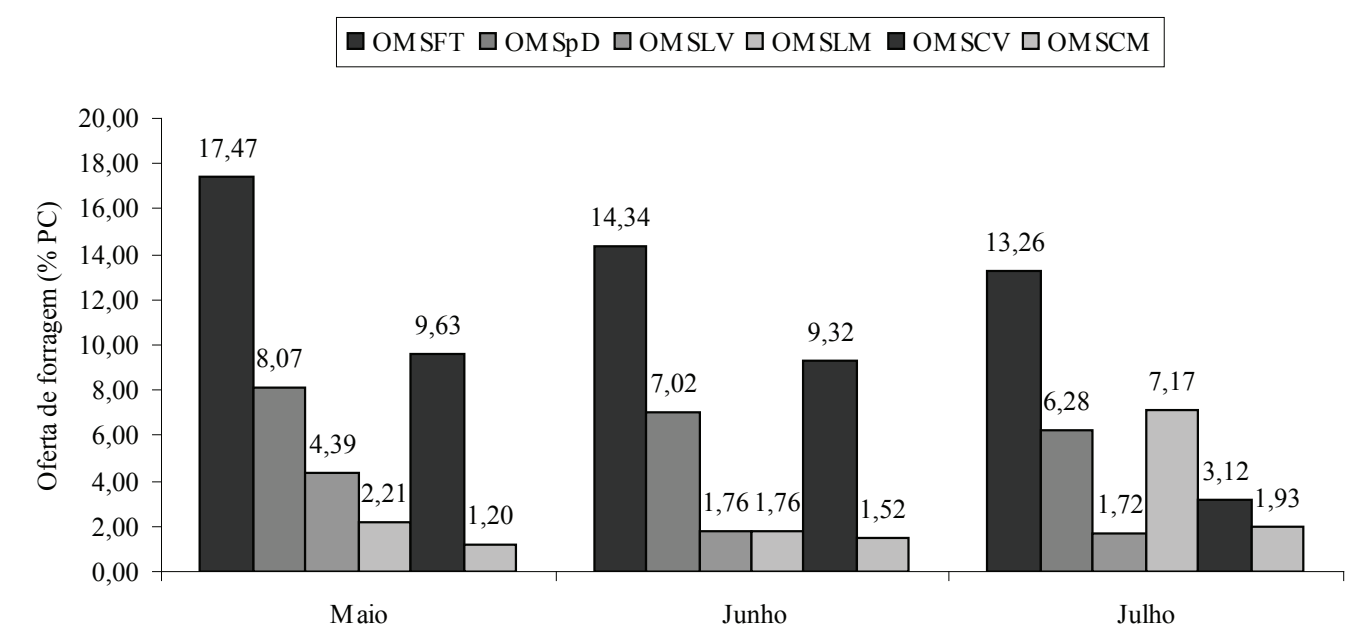

Fonte: Elaboração dos autores.

Segundo Gibb e Treacher (1976) e Hodgson (1984) o consumo de forragem é otimizado quando a oferta de forragem é maior que três a quatro vezes a capacidade de ingestão dos animais. Apesar de a OMSFT ser adequada, a OMSLV de $2,62 \%$ do PC encontra-se abaixo dos valores encontrados por 
Machado et al. (2008) que trabalhando com ofertas de forragem variando entre 4 e $16 \%$ do PC obteve o máximo desempenho animal com OMSLV entre 10 e $12 \%$ do PC.

Para Paulino, Detmann e Valadares Filho (2008) a interpretação da oferta de forragem disponível ao pastejo animal deve ser feita sob a ótica da fração potencialmente convertível em produto animal, alcançado pela utilização da OMSpd. Segundo Paulino et al. (2006) a OMSpd que potencializa o desempenho animal é de 5 a $6 \%$ do PC animal dia ${ }^{-1}$, sendo o valor médio encontrado para este experimento de $7,12 \%$, entre 1,12 e
$2,12 \%$ superior ao descrito pelo autor supracitado como ideal, o que seria responsável pelo bom desempenho alcançado pelos animais recebendo apenas a mistura mineral em relação aos animais suplementados mesmo com OMSLV considerada limitante ao desempenho animal.

O teor médio de PB de 11,58\% da forragem pastejada (Tabela 3) é função da alta precipitação pluviométrica (Tabela 1) observada no período e da adubação nitrogenada implementada que possibilitou o aumento da quantidade de folhas verdes da forragem (Figuras 1 e 2).

Tabela 3. Teores médios de matéria seca (MS\%), matéria orgânica (MO), proteína bruta (PB), matéria mineral (MM), estrato etéreo (EE), fibra em detergente neutro (FDN), carboidratos totais (CT), carboidratos não fibrosos (CNF), fibra em detergente neutro indigestível (FDNi) em amostras obtidas via simulação manual de pastejo em cada período experimental para o capim Marandu.

\begin{tabular}{lrrrr}
\hline \multirow{2}{*}{ Itens } & \multicolumn{3}{c}{ Meses experimentais } & \multirow{2}{*}{ Média } \\
\cline { 2 - 4 } & Maio & Junho & Julho & 23,09 \\
\hline MS (\%) & 25,13 & 20,83 & 23,31 & 87,11 \\
$\mathrm{MO}^{1}$ & 90,62 & 87,39 & 88,51 & 11,58 \\
$\mathrm{~PB}^{1}$ & 11,21 & 11,46 & 12,06 & 68,31 \\
$\mathrm{FDN}^{1}$ & 72,28 & 65,80 & 66,85 & 12,88 \\
$\mathrm{MM}^{1}$ & 9,38 & 12,61 & 11,49 & 1,94 \\
$\mathrm{EE}^{1}$ & 1,68 & 2,38 & 1,75 & 75,33 \\
$\mathrm{CT}^{1}$ & 77,73 & 73,55 & 74,70 & 7,01 \\
$\mathrm{CNF}^{1}$ & 5,45 & 7,75 & 7,85 & 51,37 \\
FDNi & 53,80 & 51,23 & 49,08 & 50,96 \\
NDTest $^{2}$ & 48,15 & 52,59 & 52,15 & \\
\hline
\end{tabular}

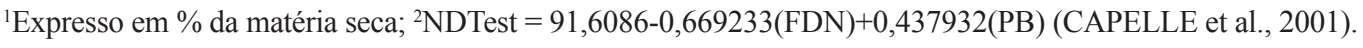

Fonte: Elaboração dos autores.

Os teores de PB situaram-se acima do mínimo necessário $(10 \% \mathrm{~PB})$ para otimizar a utilização da fibra em detergente neutro potencialmente digestível (FDNpd) no rúmem (PAULINO; DETMANN; VALADARES FILHO, 2007; DETMANN; PAULINO; VALADARES FILHO, 2010).

O teor de EE de 6,41\% (Tabela 4) para o suplemento caroço de algodão justifica-se pela grande proporção desse ingrediente $(63,00 \%)$ usado na composição do suplemento (Tabela 2). Os valores de 48,85; 58,17 e 58,79\% de FDN apresentado para os suplementos farelo de soja, grão de soja e caroço de algodão respectivamente (Tabela 4) são elevados para amostras de concentrados.

Porém deve ser considerado o ingrediente energético usado na formulação dos suplementos (Casca do grão de soja) que tem proporções elevadas de FDN fazendo com que a composição 
em fibra dos suplementos usados nesse experimento se apresentem em patamares mais elevados. A maior quantidade de FDNi para o suplemento caroço de algodão pode ser justificada pela maior proporção desse constituinte no caroço de algodão em relação aos outros ingredientes.

Tabela 4. Teores médios de matéria seca (MS\%), matéria orgânica (MO), proteína bruta (PB), fibra em detergente neutro (FDN), matéria mineral (MM), estrato etéreo (EE), Carboidratos totais (CT), Carboidratos não fibrosos (CNF) e fibra em detergente neutro indigestivel (FDNi) nos suplementos.

\begin{tabular}{cccc}
\hline \multirow{2}{*}{ Itens } & \multicolumn{3}{c}{ Suplementos } \\
\cline { 2 - 4 } & $\mathrm{SFS}^{2}$ & $\mathrm{SGS}^{3}$ & $\mathrm{SCA}^{4}$ \\
\hline $\mathrm{MS}(\%)$ & 91,13 & 90,37 & 92,96 \\
$\mathrm{MO}^{1}$ & 86,18 & 84,53 & 85,44 \\
$\mathrm{~PB}^{1}$ & 23,94 & 23,21 & 24,54 \\
$\mathrm{FDN}^{1}$ & 48,85 & 58,17 & 58,79 \\
$\mathrm{MM}^{1}$ & 13,82 & 15,47 & 14,56 \\
$\mathrm{EE}^{1}$ & 1,79 & 1,53 & 6,41 \\
$\mathrm{CT}^{1}$ & 60,45 & 59,79 & 54,49 \\
$\mathrm{CNF}^{1}$ & 16,58 & 6,60 & 0,68 \\
$\mathrm{FDNi}^{1}$ & 38,52 & 39,42 & 45,41 \\
$\mathrm{NDTest}^{5}$ & 62,40 & 63,80 & 68,11 \\
\hline
\end{tabular}

${ }^{1}$ Resultados expressos com base na matéria seca; ${ }^{2}$ Suplemento farelo de soja; ${ }^{3}$ Suplemento grão de soja; ${ }^{4}$ Suplemento caroço de algodão; ${ }^{5}$ Tabelas brasileiras de composição de alimentos para bovinos (VALADARES FILHO; PAULINO; MAGALHÃES, 2006); MM: Mistura mineral; SFS: Suplemento farelo de soja; SGS: Suplemento grão de soja; SCA: Suplemento caroço de algodão.

Fonte: Elaboração dos autores.

A suplementação proporcionou aumento $(\mathrm{P}<0,05)$ na concentração de nitrogênio amoniacal ruminal $\left(\mathrm{N}^{-\mathrm{NH}_{3}}\right)$ em $\mathrm{mg} \mathrm{dL} \mathrm{dL}^{-1}$ em relação à mistura mineral (Tabela 5). Houve efeito da suplementação $(\mathrm{P}<0,05)$ sobre as quantidades de $\mathrm{N}-\mathrm{NH}_{3}$ entre os tempos de coleta, porém sem efeito de suplemento dentro dos tempos de coleta. As quantidades de $\mathrm{N}_{-} \mathrm{NH}_{3}$ foram de 24,77; 22,31 e 29,37 mg dL-1 respectivamente para os suplementos SFS, SGS e SCA, não havendo diferença entre as quantidades de $\mathrm{N}_{-} \mathrm{NH}_{3}$ entre os suplementos fornecidos. Apesar da quantidade de PB da forragem pastejada estar acima do citado por Detmann, Paulino e Valadares Filho (2010) como adequado à fermentação da fibra em detergente neutro potencialmente digestível (FDNpd) o fornecimento de proteína extra via suplementos garantiu aumento da disponibilidade de $\mathrm{N}-\mathrm{NH}_{3}$ para microbiota ruminal. Em todos os suplementos as concentrações de amônia ruminal se mantiveram em níveis acima de $10,0 \mathrm{mg} \mathrm{dL}$ 1, considerada por Sampaio et al. (2010) como adequada para maximizar o consumo de forrageiras tropicais.

Não foram encontradas diferenças significativas $(\mathrm{P}>0,05)$ para os valores de $\mathrm{pH}$ entre suplementos e mistura mineral (Tabela 5).

Como consequência da maior concentração de $\mathrm{N}_{-} \mathrm{NH}_{3}$, a suplementação proteica aumentou $(\mathrm{P}<0,05)$ a concentração de nitrogênio ureico no plasma (NUP) em mg dL ${ }^{-1}$, quando comparada à mistura mineral, não havendo diferença entre os suplementos utilizados (Tabela 5).

Não foi observada diferença significativa $(\mathrm{P}>0,05)$ para o desempenho dos animais (Tabela 6). Os GMD foram de 0,073; 0,080; 0,070 e 0,080 $\mathrm{kg}$ animal $\mathrm{dia}^{-1}$ respectivamente, para mistura mineral, SFS, SGS e SCA. A falta de resposta 
à suplementação proteica pode ser atribuída ao adequado teor de PB da forragem, a qual permitiu manter concentração de ${\mathrm{N}-\mathrm{NH}_{3}}_{3}$ acima do valor limitante ao crescimento da microbiota ruminal.

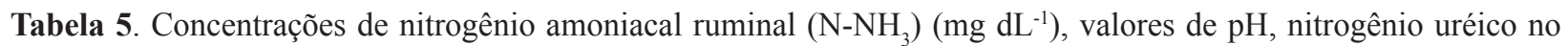
plasma (NUP) $\left(\mathrm{mg} \mathrm{dL}^{-1}\right)$, consumo de suplemento (CS) e coeficientes de variação (CV) em função dos suplementos e tempos de coleta.

\begin{tabular}{|c|c|c|c|c|c|c|}
\hline \multirow{2}{*}{ Variáveis } & \multicolumn{4}{|c|}{ Suplementos } & \multirow{2}{*}{$\mathrm{P}$} & \multirow{2}{*}{ CV $(\%)$} \\
\hline & MM & SFS & SGS & SCA & & \\
\hline $\mathrm{N}-\mathrm{NH}_{3}$ & $11,10^{\mathrm{b}}$ & $24,77^{\mathrm{a}}$ & $22,31^{\mathrm{a}}$ & $29,37^{\mathrm{a}}$ & 0,0021 & 37,15 \\
\hline $\mathrm{pH}$ & 6,16 & 6,18 & 6,25 & 6,23 & Ns & 3,77 \\
\hline NUP & $7,62^{\mathrm{a}}$ & $19,29^{\mathrm{b}}$ & $17,25^{\mathrm{b}}$ & $17,97^{b}$ & 0,005 & 2,15 \\
\hline \multirow{2}{*}{ Variáveis } & \multicolumn{4}{|c|}{ Tempos (horas) } & \multirow{2}{*}{$\mathrm{P}$} & \multirow{2}{*}{ CV $(\%)$} \\
\hline & \multicolumn{2}{|c|}{ Zero } & \multicolumn{2}{|c|}{ Quatro } & & \\
\hline $\mathrm{N}-\mathrm{NH}_{3}$ & \multicolumn{2}{|c|}{$14,11^{\mathrm{a}}$} & \multicolumn{2}{|c|}{$29,67^{b}$} & 0,009 & 37,15 \\
\hline $\mathrm{pH}$ & \multicolumn{2}{|c|}{6,29} & \multicolumn{2}{|c|}{6,21} & Ns & 3,77 \\
\hline $\mathrm{CS}\left(\mathrm{kg}\right.$ animal $\left.\mathrm{dia}^{-1}\right)$ & 0,012 & 0,250 & 0,250 & 0,250 & & \\
\hline
\end{tabular}

Valores seguidos de letras iguais na linha, não diferem pelo teste Student-Newman-Keulls a 5\% de probabilidade; MM: Mistura mineral; SFS: Suplemento farelo de soja; SGS: Suplemento grão de soja; SCA: Suplemento caroço de algodão.

Fonte: Elaboração dos autores.

Tabela 6. Valores médios de peso corporal inicial (PC Inicial) e final (PC Final), ganhos de peso total (GP Total), ganho médio diário (GMD), ganho médio diário em relação ao sal mineral (GMD Diferencial) e consumo de suplemento para os diferentes suplementos experimentais.

\begin{tabular}{lccccc}
\hline \multirow{2}{*}{ Item } & \multicolumn{4}{c}{ Suplementos } & \multirow{2}{*}{ CV $(\%)$} \\
\cline { 2 - 4 } & MM & SFS & SGS & SCA & \\
\hline PC Inicial (kg) & 22,49 & 21,30 & 21,45 & 22,06 & - \\
PC Final (kg) & 26,79 & 26,89 & 25,66 & 27,67 & - \\
GP Total (kg) & 4,3 & 5,58 & 4,21 & 5,61 & 15,02 \\
GMD (kg) & $0,073^{\mathrm{a}}$ & $0,080^{\mathrm{a}}$ & $0,070^{\mathrm{a}}$ & $0,080^{\mathrm{a}}$ & 15,02 \\
GMD Diferencial (kg) & - & 0,007 & $-0,003$ & 0,007 & - \\
Consumo de suplemento (g/dia) & 0,012 & 0,250 & 0,250 & 0,250 & - \\
\hline
\end{tabular}

Valores seguidos de letras iguais na linha, não diferem pelo teste Student-Newman-Keulls a 5\% de probabilidade; MM: Mistura mineral; SFS: Suplemento farelo de soja; SGS: Suplemento grão de soja; SCA: Suplemento caroço de algodão.

Fonte: Elaboração dos autores.

De acordo com Cabral et al. (2008b) os requisitos diários em PB estimados para animais com peso corporal de $24 \mathrm{~kg}$ e ganho diário de $80 \mathrm{~g}$ é de $97 \mathrm{~g}$, valor este próximo ao calculado de $94 \mathrm{~g} / \mathrm{dia}$, se considerarmos o teor de PB da forragem de 11,21\% e consumo diário de forragem de 3,5\% do peso corporal. Desta forma, apenas o pasto permitiria o desempenho observado, o que permite inferir que o limite do potencial genético dos animais pode ter exercido influência sobre os resultados de ganho de peso.

Os suplementos SFS e SCA propiciaram GMD 9,58\% maiores que os animais recebendo apenas mistura mineral. Ribeiro (2008) suplementando animais a 1,0\% do PC em pastagens de capim Aruana irrigado, 
com aproximadamente $9,0 \%$ de $\mathrm{PB}$ na forragem encontrou GMD de $0,121 \mathrm{~kg}$ animal $\mathrm{dia}^{-1}$ para os animais suplementados com 20,0\% de PB no suplemento, com ganho diferencial em relação à mistura mineral de $0,096 \mathrm{~g}$ animal $\mathrm{dia}^{-1}$. O GMD encontrado por Ribeiro (2008) foi 50\% superior aos encontrados nesse estudo, sendo este resultado atribuído ao baixo potencial genético dos animais e ao efeito substitutivo, que para ovinos se faz presente a partir de fornecimento de suplementos acima de $0,5 \%$ do PC em suplementos e é tanto maior quanto for a qualidade forragem pastejada pelos animais.

Para animais mantidos em pastagens de alta qualidade, existe relação direta entre as quantidades de $\mathrm{N}-\mathrm{NH}_{3}$, NUP e a reciclagem de nitrogênio, com provável impacto sobre o desempenho animal. $\mathrm{O}$ aumento na concentração de amônia ruminal em condição de dieta basal (forragem) com alta proporção de matéria orgânica digestível inibe a retirada de nitrogênio do plasma sanguíneo ou mesmo de nitrogênio corporal para o atendimento das exigências ruminais de nitrogênio amoniacal que seriam maiores em animais consumindo forragem de alta qualidade que em animais consumindo forragem de baixa qualidade. Dessa forma, mesmo em condições onde a forragem fornece PB na ordem de 10,0\%, a quantidade de $\mathrm{N}^{-\mathrm{NH}_{3}}$ nessa condição pode não ser o suficiente para atender o valor de $13,00 \mathrm{mg} \mathrm{dL}^{-1}$ de $\mathrm{N}-\mathrm{NH}_{3}$ para que não aconteça efeito da concentração de $\mathrm{N}-\mathrm{NH}_{3}$ sob a reciclagem de nitrogênio, o status proteico do rúmen e o desempenho animal. Nessa condição, o desempenho 9,58\% maior para os animais recebendo suplementos SFS e SCA em relação à mistura mineral pode ser explicada pelo aumento da concentração de $\mathrm{N}-\mathrm{NH}_{3}$ seguida por diminuição da reciclagem de NUP, hipótese esta que pode ser suportada pela menor concentração de $\mathrm{N}_{-} \mathrm{NH}_{3}$ inferior a $13,00 \mathrm{mg} \mathrm{dL} \mathrm{dL}^{-1}$ e NUP de 7,62 $\mathrm{mg} \mathrm{dL}^{-1}$ observados para mistura mineral em relação aos suplementos (DETMANN; PAULINO; VALADARES FILHO, 2010).

A partir do raciocínio acima exposto, o uso de suplementos energéticos em condições de forragem de boa qualidade na tentativa de ampliar a disponibilidade de energia de rápida fermentação para melhorar a utilização do $\mathrm{N}_{-} \mathrm{NH}_{3}$ disponível poderia colaborar ainda mais para a redução da concentração de $\mathrm{N}^{-N_{3}}$ (CARVALHO et al., 2011) e na diminuição da relação proteína bruta/nutrientes digestíveis totais da dieta. Isso pode estimular o mecanismo de reciclagem de nitrogênio em função da baixa concentração ruminal de $\mathrm{N}_{-} \mathrm{NH}_{3}$, com provável prejuízo ao desempenho animal.

O menor custo com mão-de-obra para a mistura mineral $(\mathrm{R} \$ 0,005)$ é função do seu fornecimento semanal em relação aos suplementos $(\mathrm{R} \$ 0,036)$ que foram fornecidos diariamente (Tabela 7). A maior margem bruta encontra para a mistura mineral ( R \$ 0,227) em relação aos suplementos se dá em função do menor consumo da mistura mineral em relação aos suplementos, do baixo ganho de peso diferencial dos animais suplementados em relação aos recebendo mistura mineral além do maior custo por $\mathrm{kg}$ dos suplementos utilizados. Os animais recebendo suplementos SFS e SCA atingem 30,00 $\mathrm{kg}$ PC 10 dias antes que os animais recebendo apenas a mistura mineral, o que representa menor tempo permanência nas pastagens, liberando espaço para que outro lote de animais possa ser terminado. 
Tabela 7. Indicadores econômicos e dias para atingir $30 \mathrm{~kg}$ de peso corporal.

\begin{tabular}{|c|c|c|c|c|}
\hline \multirow{2}{*}{ Indicadores Econômicos } & \multicolumn{4}{|c|}{ Suplementos } \\
\hline & MM & SFS & SGS & SCA \\
\hline Consumo suplemento $(\mathrm{kg} / \mathrm{dia})$ & 0,012 & 0,250 & 0,250 & 0,250 \\
\hline Custo por dia com mão de obra (R\$/dia) & 0,005 & 0,036 & 0,036 & 0,036 \\
\hline Custo por dia com suplemento (R\$/dia) & 0,023 & 0,158 & 0,171 & 0,129 \\
\hline Custo diário ( $\mathrm{R} \$$ ) & 0,028 & 0,194 & 0,207 & 0,165 \\
\hline Receita diária $(\mathrm{R} \$ / \text { dia })^{1}$ & 0,256 & 0,280 & 0,245 & 0,280 \\
\hline Margem bruta (R\$/dia) & 0,227 & 0,086 & 0,038 & 0,115 \\
\hline Dias para atingir $30 \mathrm{~kg}$ de $\mathrm{PC}$ & 113,28 & 103,37 & 118,14 & 103,37 \\
\hline
\end{tabular}

${ }^{1} \mathrm{O}$ valor estimado por kg de peso vivo para análise econômica foi de R\$ 3,50; MM: Mistura mineral; SFS: Suplemento farelo de soja; SGS: Suplemento grão de soja; SCA: Suplemento caroço de algodão.

Fonte: Elaboração dos autores.

Ribeiro (2008) suplementando borregos em pastos de capim Aruana irrigados encontrou margem bruta superior para os animais recebendo suplemento com 20,0\% de PB (R \$ 2,02) em relação aos animais recebendo mistura mineral $(\mathrm{R} \$ 1,94)$ contrariamente aos resultados encontrados para este experimento, porém para os dados de Ribeiro (2008) o ganho de peso diferencial entre a mistura mineral e o suplemento com $20,0 \%$ de PB foi de $0,096 \mathrm{~kg}$ animal $\mathrm{dia}^{-1}$. Dessa forma duas variáveis devem consideradas em avaliações econômicas da prática da suplementação de animais mantidos em forragem de alta qualidade: magnitude do ganho de peso diferencial da suplementação em relação a mistura mineral, desocupação das pastagens e custo diário da suplementação (mão de obra e suplemento) para que decisões equivocadas não sejam tomadas e o uso da suplementação desconsiderada erroneamente.

\section{Conclusões}

A utilização da suplementação com qualquer uma das fontes proteicas testadas não provou aumento no ganho de peso dos animais bem como não provou alterações bruscas no $\mathrm{pH}$ ruminal a valores limitantes ao crescimento microbiano. Em pastos com alta disponibilidade de forragem apenas a suplementação com mistura mineral é suficiente para alcançar o desempenho animal aqui obtido.

\section{Referências}

BRÂNCIO, P. A.; EUCLIDES, V. P. B.; NASCIMENTO JUNIOR, D.; FONSECA, D. M.; ALMEIDA, R. G.; MACEDO, M. C. M.; BARBOSA, R. A. Avaliação de três cultivares de Panicum maximum Jacq. sob pastejo: comportamento ingestivo de bovinos. Revista Brasileira de Zootecnia, Viçosa, MG, v. 32, n. 5, p. 1045-1053, 2003.

CABRAL, L. S.; NEVES, E. M. O.; ZERVOUDAKIS, J. T.; ABREU, J. G.; RODRIGUES, R. C.; SOUZA, A. L.; OLIVEIRA, I. S. Estimativas dos requisitos nutricionais de ovinos em condições brasileiras. Revista Brasileira de Saúde Produção Animal, Salvador, v. 9, n. 3, p. 529-542, jul./set. 2008 b.

CABRAL, L. S.; ZERVOUDAKIS, J. T.; COPPEDÊ, C. M.; SOUZA, A. L.; CARAMORI JÚNIOR, J. G.; POLIZEL NETO, A.; OLIVEIRA, I. S. Suplementação de bovinos de corte mantidos em pastagem de Panicum maximum cv. Tanzânia-1 no período das águas. Revista Brasileira de Saúde Produção Animal, Salvador, v. 9, n. 2, p. 293-302, abr./jun. 2008a.

CAPELLE, E. R.; VALADARES FILHO, S. C.; SILVA, J. F. C.; CECON, P. R. Estimativas do valor energético a partir de características químicas e bromatológicas dos alimentos. Revista Brasileira de Zootecnia, Viçosa, MG, v. 30, n. 6, p. 1837-1856, 2001.

CASALI, A. O.; DETMANN, E.; VALADARES FILHO, S. de C.; PEREIRA, J. C.; HENRIQUES, L. T.; FREITAS, S. G.; PAULINO, M. F. Influência do tempo de incubação e do tamanho de partículas sobre os teores de compostos indigestíveis em alimentos e fezes bovinas obtidos por procedimento in situ. Revista Brasileira de Zootecnia, Viçosa, MG, v. 37, n. 2, p. 335-342, 2008. 
CARVALHO, D. M. G.; CABRAL, L. S.; ZERVOUDAKIS, J. T.; ARNOLDO, T. L. Q.; BENATTI, J. M. B.; KOSCHECK, J. F. W.; PIONA, M. N. M.; OLIVEIRA, A. A. Suplementos para ovinos mantidos em pastos de capim - marandu. Pesquisa Agropecuária Brasileira, Brasília, v. 46, n. 2, p. 196-204, fev. 2011.

DETMANN, E.; PAULINO, M. F.; VALADARES FILHO, S. C. Otimização do uso de recursos forrageiros basais. In: SIMPÓSIO DE PRODUÇÃO DE GADO DE CORTE - SIMCORTE, 7., 2010, Viçosa, MG. Anais... Viçosa, MG: UFV, 2010.

EUCLIDES, V. B. P.; CARDOSO, E. G.; MACEDO, M. C. M.; OLIVEIRA, M. P. Consumo voluntário de Brachiaria decumbens cv. Basilisk e Brachiaria brizantha cv. Marandu sob pastejo. Revista Brasileira de Zootecnia, Viçosa, MG, v. 29, n. 6, p. 2200-2208, 2000. Suplemento 2.

EUCLIDES, V. P. B.; RAFFI, A. S.; COSTA, F. P.; EUCLIDES FILHO, K. FIGUEIREDO, G. R.; COSTA, J. A. R. Eficiências biológica e econômica de bovinos em terminação alimentados com dieta suplementar em pastagem de capim marandu. Pesquisa Agropecuária Brasileira, Brasília, v. 44, n. 11, p. 1536-1544, nov. 2009.

GIBB, M. J.; TREACHER, T. T. The effect of herbage allowance on herbage intake and performance of lambs grazing perennial ryegrass and redclover swards. Journal of Agricultural Science, Cambridge, v. 86, n. 1, p. 355$365,1976$.

HALL, M. B. Calculation of non-structural carbohydrate content of feeds that contain non protein nitrogen. Gainesville: University of Florida, 2000. p. A-25 (Bulletin, 339).

HODGSON, J. Sward conditions, herbage allowance and animal production: an evaluation of research results. Proceedings of New Zealand Society of Animal Production, Hamilton, v. 44, n. 1, p. 99-104, 1984.

LAZZARINI, I.; DETMANN, E.; SAMPAIO, C. B.; PAULINO, M. F.; VALADARES FILHO, S. C.; SOUZA, M. A.; OLIVEIRA, F. A. Intake and digestibility in cattle fed low-quality tropical forage and supplemented with nitrogenous compounds. Revista Brasileira de Zootecnia, Viçosa, MG, v. 38, n. 10, p. 2021-2030, 2009.

MACHADO, L. A. Z.; FABRÍCIO, A. C.; GOMES, A.; ASSIS, P. G. G.; LEMPP, B.; MARASCHIN, G. E. Desempenho de animais alimentados com lâminas foliares, em pastagem de capim-marandu. Pesquisa Agropecuária Brasileira, Brasília, v. 43, n. 11, p. 16091616, nov. 2008.

MINSON, D. J. Forage in ruminant nutrition. Queensland: Academic Press, 1990. 483 p.
PAULINO, M. F.; ZAMPERLINI, B.; FIGUEIREDO, D. M.; MORAES, E. H. B. K.; VALADARES FILHO, S.; DETTEMAN, E. Bovinocultura de precisão em pastagens. In: SIMPÓSIO DE PRODUÇÃO DE GADO DE CORTE - SIMCORTE, 6., 2006, Viçosa, MG. Anais... Viçosa, MG: UFV, 2006. p. 145-167.

PAULINO, M. F.; DETMANN, E.; VALADARES FILHO, S. C. Suplementação animal em pasto: energética ou proteica? In: SIMPÓSIO DE FORRAGICULTURA E PASTAGEM - SIMFOR, 2007, Viçosa, MG. Anais... Viçosa, MG: UFV, 2007. p. 123-146.

PAULINO, M. F.; DETMANN, E.; VALADARES FILHO, S. C. Bovinocultura funcional nos trópicos. In: SIMPÓSIO DE PRODUÇÃO DE GADO DE CORTE SIMCORTE, 6., 2008, Viçosa, MG. Anais... Viçosa, MG: UFV, 2008. p. 211-245.

PORTO, M. O.; PAULINO, M. F.; VALADARES FILHO, S. C.; SALES, M. F. L.; LEÃO, M. I.; COUTO, V. R. M. Fontes suplementares de proteína para novilhos mestiços em recria em pastagens de capim-braquiária no período das águas: desempenho produtivo e econômico. Revista Brasileira de Zootecnia, Viçosa, MG, v. 38, n. 8, p. 1553-1560, 2009.

RIBEIRO, P. P. O. Niveis de proteina em suplementos múltiplos para ovinos manejados em pastagem de Panicum maximum Jaqc cv. Aruana na época seca. 2008. Dissertação (Mestrado em Ciência Animal) - Faculdade de Agronomia e Medicina Veterinária. Universidade Federal de Mato Grosso, Cuiabá.

SAMPAIO, C. B.; DETMANN, E.; PAULINO, M. F.; VALADARES FILHO, S. C.; SOUZA, M. A.; LAZZARINI, I.; PAULINO, P. V. R.; QUEIROZ, A. C. Intake and digestibility in cattle fed low-quality tropical forage and supplemented with nitrogenous compounds. Tropical Animal Health and Production, Edinburgh, v. 42, n. 6, p. 1471-1479, 2010.

SNIFFEN, C. J.; O'CONNOR, J. D.; VAN SOEST, P. J.; FOX, D. G.; RUSSELL, J. B. A net carbohydrate and protein system for evaluating cattle diets: II. Carbohydrate and protein availability. Journal of Animal Science, Champaign, v. 70, n. 11, p. 3562-3577, 1992.

SILVA, D. J.; QUEIROZ, A. C. Análise de alimentos: métodos químicos e biológicos. 3. ed. Viçosa, MG: Universidade Federal de Viçosa, 2002. 165 p.

TRINDADE, J. K.; SILVA, S. C.; SOUZA JUNIOR, S. J.; GIACOMINI, A. A.; ZEFERINO, C. V.; GUARDA, V. D. A.; CARVALHO, P. C. F. Composição morfológica da forragem consumida por bovinos de corte durante o rebaixamento do capim marandu submetido a estratégias de pastejo rotativo. Pesquisa Agropecuária Brasileira, Brasília, v. 42, n. 2, p. 883-890, 2007. 
UNIVERSIDADE FEDERAL DE VIÇOSA - UFV. VALADARES FILHO, S. C.; PAULINO, P. V. R.; SAEG - Sistema de análises estatísticas e genética. MAGALHÃES, K. A. Exigências nutricionais de Viçosa, MG: UFV, 2001. (Manual do usuário). zebuinos e tabela de composição de alimentos. BRCORTE. Viçosa, MG: Universidade Federal de Viçosa, 2006. 